\title{
Reductive Conversion of Biomass-Derived Furancarboxylic Acids with Retention of Carboxylic Acid Moiety
}

\author{
Yoshinao Nakagawa $^{1,2} \cdot$ Mizuho Yabushita $^{1} \cdot$ Keiichi Tomishige $^{1,2}$
}

Received: 12 January 2021 / Revised: 7 February 2021 / Accepted: 12 February 2021 / Published online: 22 March 2021

(c) The Author(s) 2021

\begin{abstract}
Catalytic reduction systems of 2-furancarboxylic acid (FCA) and 2,5-furandicarboxylic acid (FDCA) with $\mathrm{H}_{2}$ without reduction of the carboxyl groups are reviewed. FCA and FDCA are produced from furfural and 5-hydroxymethylfurfural which are important platform chemicals in biomass conversions. Furan ring hydrogenation to tetrahydrofuran-2-carboxylic acid (THFCA) and tetrahydrofuran-2,5-dicarboxylic acid (THFDCA) easily proceeds over Pd catalysts. Hydrogenolysis of one $\mathrm{C}-\mathrm{O}$ bond in the furan ring produces 5-hydroxyvaleric acid (5-HVA) and 2-hydroxyadipic acid. 2-Hydroxyvaleric acid is not produced in the reported systems. 5-HVA can be produced as the lactone form ( $\delta$-valerolactone; DVL) or as the esters depending on the solvent. These reactions proceed over Pt catalysts with good yields $(\sim 70 \%)$ at optimized conditions. Hydrogenolysis of two $\mathrm{C}-\mathrm{O}$ bonds in the furan ring produces valeric acid and adipic acid, the latter of which is a very important chemical in industry and its production from biomass is of high importance. Adipic acid from FDCA can be produced directly over Pt-MoO cata- $^{-}$ lyst, indirectly via hydrogenation and hydrodeoxygenation as one-pot reaction using the combination of $\mathrm{Pt}$ and acid catalysts such as Pt/niobium oxide, or indirectly via two-step reaction composed of hydrogenation catalyzed by Pd and hydrodeoxygenation catalyzed by iodide ion in acidic conditions. Only the two-step method can give good yield of adipic acid at present.
\end{abstract}

Keywords Biomass $\cdot$ Hydrogenolysis $\cdot$ Furanic compound $\cdot$ Carboxylic acid

\section{Introduction}

Utilization of biomass as source of chemicals has received much attention because of the depletion of fossil resources and global warming issue. Generally, biomass resources have complex structure and contain various minor components. Therefore, the use of "platform chemicals," which can be readily synthesized in pure form from biomass, as intermediates is a typical approach to synthesizing useful chemicals from biomass [1-3]. Typical platform chemicals in biomass utilization include carboxylic acids, sugar alcohols

Yoshinao Nakagawa

yoshinao@erec.che.tohoku.ac.jp

$\triangle$ Keiichi Tomishige

tomi@erec.che.tohoku.ac.jp

1 Department of Applied Chemistry, School of Engineering, Tohoku University, 6-6-07 Aoba, Aramaki, Aoba-ku, Sendai 980-8579, Japan

2 Research Center for Rare Metal and Green Innovation, Tohoku University, 468-1, Aoba, Aramaki, Aoba-ku, Sendai 980-0845, Japan and furanic compounds. In particular, furanic compounds are very important because they can be synthesized from inedible lignocellulosic biomass and can be converted into various compounds [4-8]. The most basic biomass-derived furanic compounds are furfural and 5-hydroxymethylfurfural (HMF), which are produced by dehydration of pentoses and hexoses, respectively. Furfural has been already industrially manufactured from pentose-rich hemicellulose component of lignocellulose. While fructose dehydration is the easiest method to produce $\mathrm{HMF}$, it is possible to produce HMF from glucose or even cellulose, both of which are more common biomass constituents than fructose, and enormous efforts to investigate such methods have been devoted in these years. Furfural and HMF have reactive unsaturated furan ring and aldehyde group, and the conversion of furfural and HMF has been also intensively investigated by using various reactions such as reduction, oxidation, addition and condensation. While reductive conversion has been the most investigated because of the high unsaturation of furfural and HMF and variety of products $[4,6-10]$, oxidation of the side chain of furfural and HMF can give furancarboxylic acids, namely 2-furancarboxylic acid (furoic acid; FCA) and 2,5-furandicarboxylic 
acid (FDCA), respectively, relatively easily (Fig. 1). While typical oxidation systems of furfural and HMF with $\mathrm{O}_{2}$ require excess amount of base which needs neutralization after reaction [11, 12], several recently reported systems using $\mathrm{O}_{2}$ and catalysts such as $\mathrm{Pt}$ [13-15], Au/basic oxides [16-21], $\mathrm{Ru}$ [22] and Mn compounds [23-25] can give excellent yield of FCA and FDCA even without base. FDCA has attracted much attention as a monomer of polyester, polyethylene 2,5-furandicarboxylate (PEF) which is an analogue of the most used polyester, polyethylene terephthalate (PET) [26-28]. While furfural and HMF are gradually polymerized during storage, FCA and FDCA are stable solids. However, the utilization of FCA or FDCA as sources of other chemicals has been much less investigated. Because FCA and FDCA are in a high oxidation level, the reduction of FCA and FDCA is an important reaction in the utilization. However, if the carboxyl groups of FCA or FDCA are reduced, the advantage of the use of FCA or FDCA as a reactant is lost because the products can be also synthesized from furfural or HMF with smaller amount of reducing agent. Therefore, the reduction of the furan ring of FCA and FDCA with retention of the carboxyl groups is more important. Recently, our group and several other research groups have reported such reductive conversions. In this paper, we review the chemical reductive conversions of FCA and FDCA with retention of the carboxyl groups in three categories: hydrogenation of the furan ring,

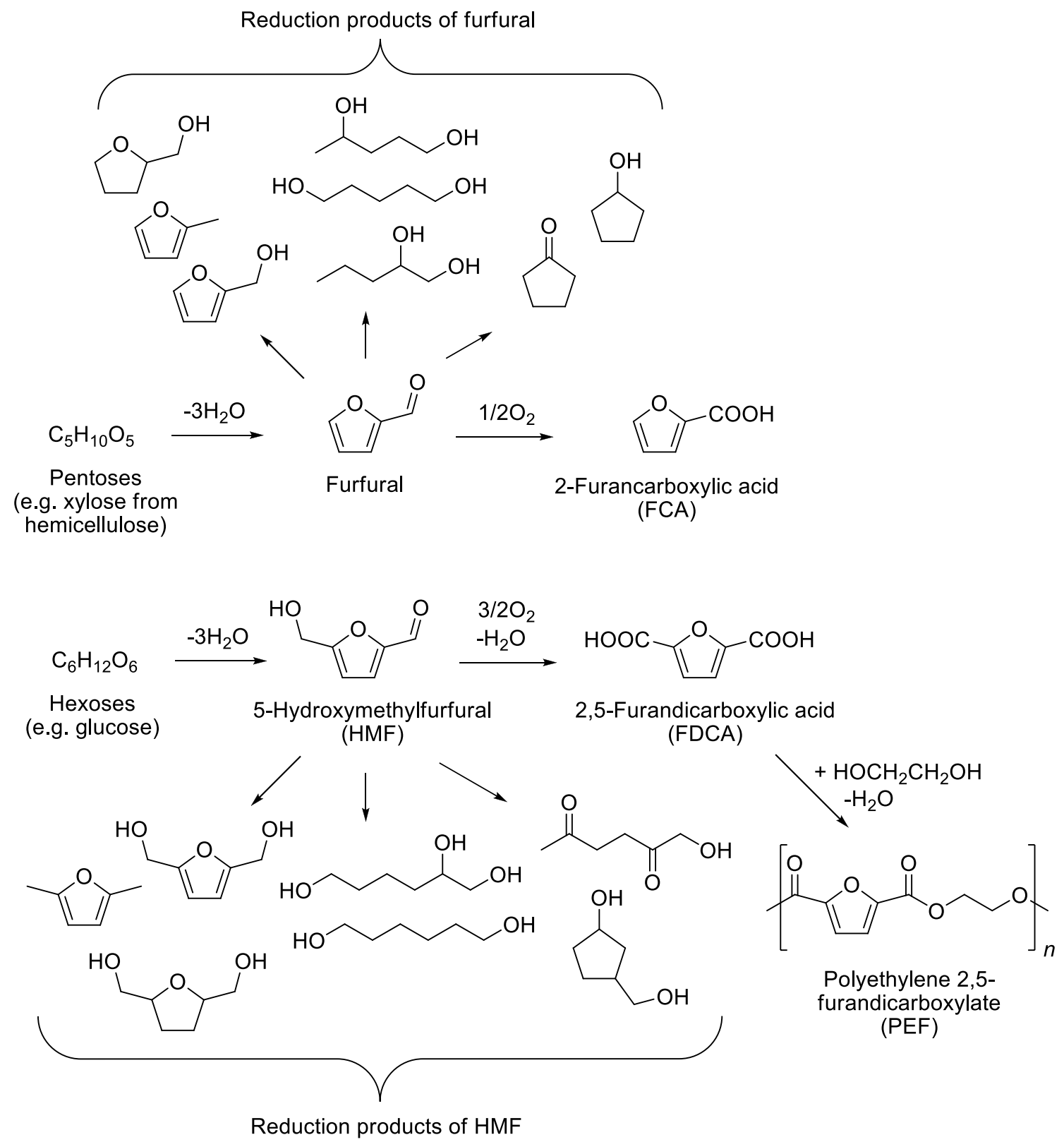

Fig. 1 Utilization of furfural and HMF including oxidation to FCA and FDCA 
$\mathrm{C}-\mathrm{O}$ hydrogenolysis in the furan ring and $\mathrm{C}-\mathrm{O}$ hydrogenolysis after hydrogenation of the furan ring. The systems for the most important products, adipic acid, 5-hydroxyvaleric acid and valeric acid, are compared with other production methods from biomass.

\section{Hydrogenation of Furan Ring}

Hydrogenation of the furan ring in FCA and FDCA produces tetrahydrofuran-2-carboxylic acid (THFCA; Eq. 1) and tetrahydrofuran-2,5-dicarboxylic acid (THFDCA; Eq. 2), respectively. While hydrogenation of $\mathrm{C}=\mathrm{C}$ bonds is easy over various noble metal catalysts, $\mathrm{Pd}$ is known to be less active in hydrogenation of $\mathrm{C}=\mathrm{O}$ bonds than other noble metals [29]. Indeed, simple Pd catalysts are effective in $\mathrm{C}=\mathrm{C}$ hydrogenation of FCA and FDCA to THFCA and THFDCA, respectively, with very high selectivity (e.g., > 99\%) [30-33]. For FDCA, only cis-isomer is produced because of the general syn hydrogenation mechanism catalyzed by metal surfaces [32, 34]. Wide range of solvents can be used, including $\mathrm{H}_{2} \mathrm{O}$, alcohols, acetic acid and toluene. However, at high reaction temperature (e.g., $373 \mathrm{~K}$ ), alcohol solvents lead to esterification of the hydrogenated products $[35,36]$. Since FDCA has low solubility in $\mathrm{H}_{2} \mathrm{O}$, acetic acid has been typically used as solvent in Refs. [31, 32]. A typical run of FDCA hydrogenation is shown in Eq. (3) [32]. Our group [36] and Liu et al. [33] reported the effect of noble metal type on the catalytic FCA reduction, and both groups reported that Pd catalyst has higher selectivity to THFCA than other noble metal catalysts ( $\mathrm{Pt}, \mathrm{Ru}, \mathrm{Rh}$ and Ir). The main side reaction over the non-Pd noble metal catalysts is the ring opening to 5-hydroxyvaleric acid or its derivatives, which will be discussed in the next section.<smiles>O=C(O)c1ccco1</smiles>

THFCA has an asymmetric carbon atom at 2-position, and therefore, asymmetric hydrogenation of FCA was also investigated. Baiker et al. [30, 37] tested the combination of $\mathrm{Pd} / \mathrm{Al}_{2} \mathrm{O}_{3}$ catalyst and various chiral additives; however, the reported enantioselectivity was not satisfactory (maximum ee $42 \%$, with cinchonidine as a chiral additive). There is another report using $\mathrm{Rh}$ complex catalyst with a chiral ferrocenyl diphosphine ligand; however, the reported enantioselectivity was also low (ee 24\%) [38].

\section{Ring-Opening Hydrogenolysis}

Hydrogenolysis is the reaction composed of bond dissociation and the addition of $\mathrm{H}$ atoms to both the produced terminal atoms, although the positions of $\mathrm{H}$ atoms incorporated to the products from $\mathrm{H}_{2}$ might not be the same as that of the dissociated bond. C-O hydrogenolysis of furan compounds initially opens their ring and subsequently $\mathrm{C}=\mathrm{C}$ bonds in chain structure undergo hydrogenation to be saturated structure, since $\mathrm{C}=\mathrm{C}$ bonds in chain structure are more easily hydrogenated than those in aromatic ring structure. The possible products of $\mathrm{C}-\mathrm{O}$ hydrogenolysis of FCA and FDCA are summarized in Fig. 2. Hydrogenolysis of one $\mathrm{C}-\mathrm{O}$ bond in FCA produces 5-hydroxyvaleric acid (5-HVA) or 2-hydroxyvaleric acid (2-HVA). 5-Hydroxyvaleric acid can be reversibly converted to the lactone form, $\delta$-valerolactone (DVL). Only the hydrogenolysis to 5-HVA and its derivatives (DVL, ester of 5-HVA and solvent) has been reported, and there is no report describing the FCA hydrogenolysis to 2-HVA at present. This is in contrast to a related reaction, furfuryl alcohol hydrogenolysis to pentanediols where both 1,5-pentanediol and 1,2-pentanediol are the main products depending on the catalyst $[8,39-41]$. One explanation for the preferential $\mathrm{C}-\mathrm{O}$ dissociation at 1,2-position to 5-HVA is that the carbonyl (carboxyl) group adsorbed on the catalyst directs the position of hydrogen atom addition to the neighboring<smiles>O=C(O)c1ccc(C(=O)OCc2ccco2)o1</smiles><smiles>O=C(O)c1ccc(C(=O)O)o1</smiles>

$5 \mathrm{~g}$
$\mathrm{Pd} / \mathrm{C}(10 \mathrm{wt} \% \mathrm{Pd}) 0.51 \mathrm{~g}$ AcOH $50 \mathrm{~mL}, \mathrm{H}_{2}$ balloon, $333 \mathrm{~K}, 69 \mathrm{~h}$

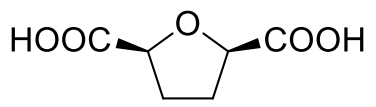

Quant. 
Fig. 2 Hydrogenolysis products of FCA and FDCA. Reduction products of the carboxyl groups are omitted. Arrows represent $\mathrm{C}-\mathrm{O}$ hydrogenolysis unless otherwise noted
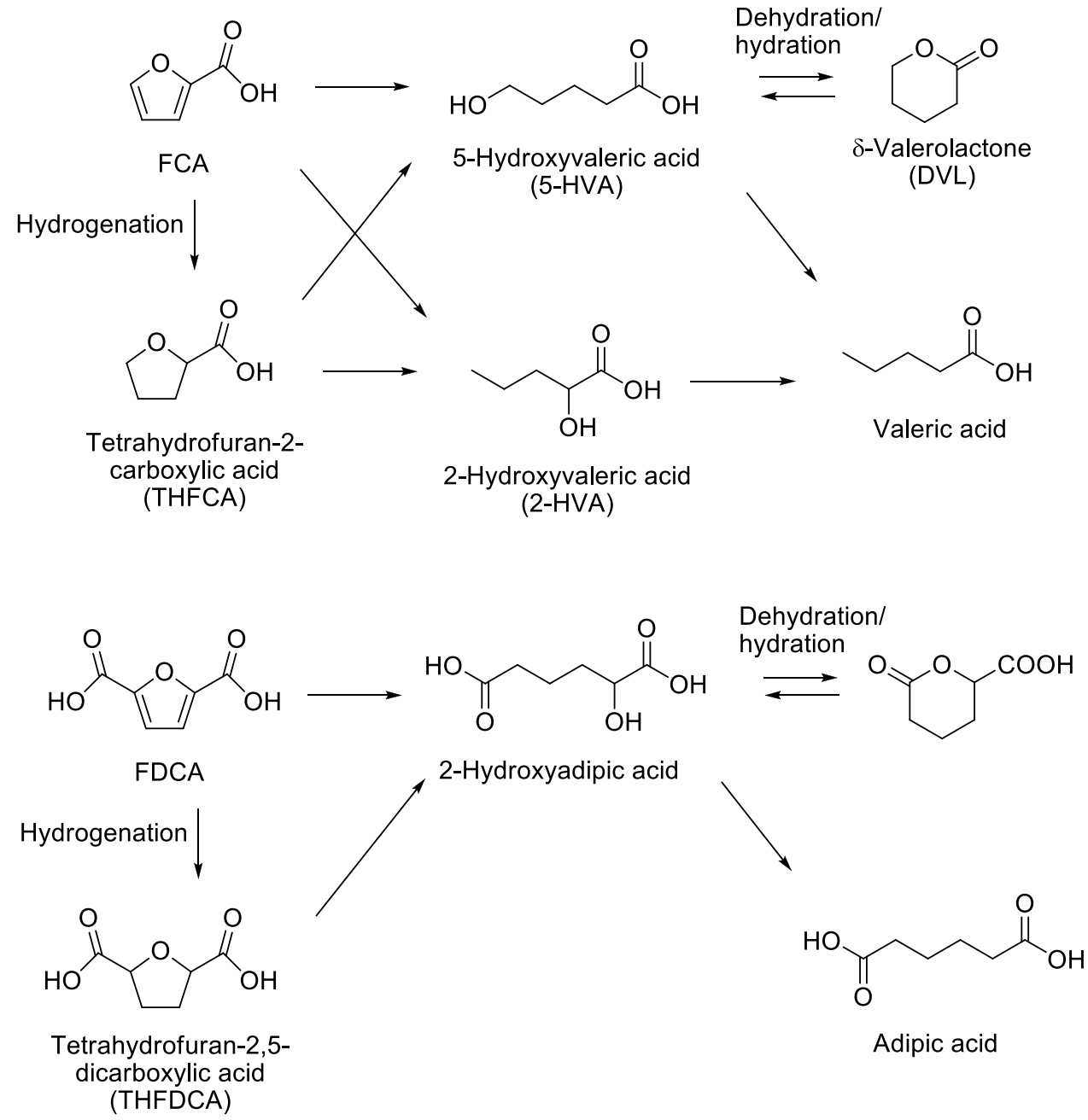

position of the carbonyl group. The mechanism for the selective $\mathrm{C}-\mathrm{O}$ hydrogenolysis will be discussed later. In the case of FDCA, hydrogenolysis of one $\mathrm{C}-\mathrm{O}$ bond produces 2-hydroxyadipic acid. The lactone form of 2-hydroxyadipic acid is also probably generated, although such formation has not yet been confirmed because the literature studies for FDCA hydrogenolysis used water solvent that suppresses the formation of lactones.

An old report [42] in 1949 describing the effectiveness of Adams catalyst $\left(\mathrm{PtO}_{2}\right)$ in hydrogenation of various substrates showed that the reduction of FCA with Adams catalyst and $\mathrm{H}_{2}$ in acetic acid solvent produced DVL. However, the detailed procedure and yield and selectivity values were not described in this report, and this reaction had not received attention for long time until the recent days when biomass conversion has great importance. Very recently, our group [36] and Liu et al. [33] reported the detailed study of Ptcatalyzed C-O hydrogenolysis of FCA to 5-HVA and its derivatives (DVL and ester of 5-HVA) almost at the same time. Our group investigated the effects of support and solvent (Table 1) as well as reaction conditions. Although both the effects of support and solvent are not large, $\mathrm{Pt} / \mathrm{Al}_{2} \mathrm{O}_{3}$ catalyst shows relatively high activity and selectivity to 5-HVA derivatives, and polar solvents such as methanol give higher selectivity. Ester of 5-HVA becomes the main product when smaller alcohols such as methanol are used as the solvent. The highest combined yield of 5-HVA and its derivatives is $62 \%$ (methyl 5-hydroxyvalerate 55\%, DVL $7 \%, 5$-HVA $<0.1 \%$ ). Acetic acid solvent, which was used in the old report using Adams catalyst [42], surely gives good selectivity to DVL (66\%); however, the reaction rate in acetic acid is lower than that in alcohols. Liu et al. [33] reported Pt-catalyzed FCA hydrogenolysis in water solvent. Although water solvent was less effective to obtain high selectivity than methanol solvent in our study [36], high selectivity to 5-HVA was reported with $\mathrm{Pt} / \mathrm{SiO}_{2}$ catalyst with relatively large Pt particle sizes ( $>4 \mathrm{~nm}$ ) [33]. The highest yield of 5 -HVA reached $78 \%$. The stability of the catalysts was investigated in these two studies. The catalysts $\left(\mathrm{Pt} / \mathrm{Al}_{2} \mathrm{O}_{3}\right.$ and $\mathrm{Pt} /$ $\mathrm{SiO}_{2}$ ) can be reused without large loss of activity or selectivity when the catalyst is calcined at $573 \mathrm{~K}$ as regeneration, although the direct reuse of $\mathrm{Pt} / \mathrm{Al}_{2} \mathrm{O}_{3}$ without calcination 
Table 1 Reduction of FCA over various catalysts and solvent [36]

\begin{tabular}{|c|c|c|c|c|c|c|c|c|}
\hline \multirow[t]{2}{*}{ Catalyst } & \multirow[t]{2}{*}{ Solvent } & \multirow[t]{2}{*}{ Conv. (\%) } & \multicolumn{6}{|l|}{ Selectivity (\%) } \\
\hline & & & Ester of 5-HVA & 5-HVA & DVL & $\begin{array}{l}\text { Ester of } \\
\text { THFCA }\end{array}$ & THFCA & Others \\
\hline $\mathrm{Pt} / \mathrm{Al}_{2} \mathrm{O}_{3}$ & Methanol & 91 & 51 & $<0.1$ & 6 & 12 & 10 & $<1$ \\
\hline $\mathrm{Pt} / \mathrm{Al}_{2} \mathrm{O}_{3}{ }^{\mathrm{a}}$ & Methanol & $>99$ & 55 & $<0.1$ & 7 & 20 & 2 & 1 \\
\hline $\mathrm{Pt} / \mathrm{ZrO}_{2}$ & Methanol & 58 & 46 & $<0.1$ & 4 & 13 & 6 & $<1$ \\
\hline $\mathrm{Pt} / \mathrm{CeO}_{2}$ & Methanol & 91 & 37 & $<0.1$ & 7 & 10 & 24 & $<1$ \\
\hline $\mathrm{Pt} / \mathrm{TiO}_{2}$ & Methanol & 25 & 38 & $<0.1$ & 5 & 8 & 8 & 3 \\
\hline $\mathrm{Pt} / \mathrm{SiO}_{2}$ & Methanol & 34 & 34 & $<0.1$ & 6 & 5 & 23 & $<1$ \\
\hline $\mathrm{Pt} / \mathrm{C}$ & Methanol & 16 & 24 & $<0.1$ & 6 & 5 & 25 & 1 \\
\hline $\mathrm{Rh} / \mathrm{C}$ & Methanol & $>99$ & 6 & $<0.1$ & $<1$ & 26 & 60 & $<1$ \\
\hline $\mathrm{Ru} / \mathrm{C}$ & Methanol & $>99$ & 6 & $<0.1$ & $<1$ & 23 & 61 & $<1$ \\
\hline $\mathrm{Pd} / \mathrm{C}$ & Methanol & 93 & $<0.1$ & $<0.1$ & $<0.1$ & 8 & 89 & $<1$ \\
\hline $\mathrm{Pt} / \mathrm{Al}_{2} \mathrm{O}_{3}$ & Ethanol & 90 & 44 & $<1$ & 13 & 3 & 19 & $<1$ \\
\hline $\mathrm{Pt} / \mathrm{Al}_{2} \mathrm{O}_{3}$ & 1-Propanol & 96 & 27 & 3 & 24 & 1 & 23 & $<1$ \\
\hline $\mathrm{Pt} / \mathrm{Al}_{2} \mathrm{O}_{3}$ & 2-Propanol & 97 & 4 & 5 & 42 & $<1$ & 27 & $<1$ \\
\hline $\mathrm{Pt} / \mathrm{Al}_{2} \mathrm{O}_{3}$ & 1,4-Dioxane & 88 & - & 5 & 34 & - & 35 & $<1$ \\
\hline $\mathrm{Pt} / \mathrm{Al}_{2} \mathrm{O}_{3}$ & Acetic acid & 55 & - & $<0.1$ & 66 & - & 27 & 1 \\
\hline $\mathrm{Pt} / \mathrm{Al}_{2} \mathrm{O}_{3}$ & Water & 99 & - & 4 & 33 & - & 30 & 6 \\
\hline
\end{tabular}

Reaction conditions: catalyst ( $4 \mathrm{wt} \%$ noble metal) $50 \mathrm{mg}$ (for noble metal/C: $40 \mathrm{mg}$ of $5 \mathrm{wt} \%$ noble metal catalyst), FCA $10 \mathrm{mmol}$, solvent $29 \mathrm{~g}, \mathrm{H}_{2} 4 \mathrm{MPa}$ (at room temp.), $373 \mathrm{~K}, 1 \mathrm{~h} .{ }^{\mathrm{a}} 4 \mathrm{~h}$. FCA=2-furancarboxylic acid, $\mathrm{HVA}=$ hydroxyvaleric acid, $\mathrm{DVL}=\delta$-valerolactone, $\mathrm{THFCA}=$ tetrahydrofuran-2-carboxylic acid gradually decreases the activity due to deposition of organic compounds on the catalyst surfaces.

The reaction mechanism was discussed based on the reactivity of various related substrates over $\mathrm{Pt} / \mathrm{Al}_{2} \mathrm{O}_{3}$ in methanol [36]. The control reaction of THFCA does not give $\mathrm{C}-\mathrm{O}$ hydrogenolysis products but only gives methyl tetrahydrofuran-2-carboxylate which is the ester of THFCA and methanol solvent. This result indicates that the $\mathrm{C}-\mathrm{O}$ hydrogenolysis which opens the furan ring occurs before total hydrogenation of the furan ring. The reactivity of methyl 2-furancarboxylate, which is the ester of FCA and methanol, is similar to that of FCA: conversion and selectivity to methyl 5-hydroxyvalerate are similar to those from FCA. This result shows that the carboxyl proton in FCA does not play a critical role in the hydrogenolysis. In the case of furan-3-carboxylic acid, the reactivity is much lower than that of FCA; nevertheless, the $\mathrm{C}-\mathrm{O}$ hydrogenolysis product is formed to some extent as the lactone form (Eq. 4): $22 \%$ conversion and $8 \%$ yield of 2-methyl- $\gamma$-butyrolactone was obtained, while in the same conditions FCA was converted to methyl 5 -hydroxyvalerate with $47 \%$ yield at $91 \%$ conversion. The position of the carboxyl group much affects the reactivity.<smiles>O=C(O)c1ccoc1</smiles>

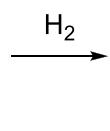<smiles>CC(CCO)C(=O)O</smiles>
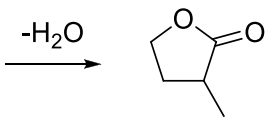

In order to determine whether dihydrofuran derivatives are involved in the catalysis, the reactions of furan, 2,3-dihydrofuran and 2,5-dihydrofuran over $\mathrm{Pt} / \mathrm{Al}_{2} \mathrm{O}_{3}$ were tested (Table 2) [36]. The reactions were carried out by introducing $\mathrm{H}_{2}$ after heating to the reaction temperature ( $373 \mathrm{~K}$ ) because the hydrogenation of these substrates to THF is very fast and completed during heating in the presence of $\mathrm{H}_{2}$. In the reaction of furan, the $\mathrm{C}-\mathrm{O}$ hydrogenolysis product, 1-butanol, is obtained in moderate yield (41\%) as well as the total hydrogenation product THF ( $40 \%$ yield). From dihydrofurans, the 1-butanol yield is much lower, and 2-methoxytetrahydrofuran, which is the product of methanol addition, and THF are mainly produced from 2,3-dihydrofuran and 2,5-dihydrofuran, respectively. These results suggest that $\mathrm{C}-\mathrm{O}$ hydrogenolysis of furan mainly occurs before addition of two hydrogen atoms. The $\mathrm{C}-\mathrm{O}$ hydrogenolysis starts with addition of one hydrogen atom to the furan ring, and then, the $\mathrm{C}-\mathrm{O}$ bond is dissociated. From 2,5-dihydrofuran, significant amount of the $\mathrm{C}-\mathrm{O}$ hydrogenolysis product (1-butanol) is formed, although it is much lower than that from furan. This result suggests that the $\mathrm{C}-\mathrm{O}$ hydrogenolysis can occur after addition of one hydrogen atom to 2,5-dihydrofuran, i.e., formation of 2,3,5-trihydrofuran intermediate which possesses a radical at 3-position. Altogether, we assume that $\mathrm{C}-\mathrm{O}$ hydrogenolysis of furan and furancarboxylic acids occurs after addition of one hydrogen atom at the 2-position, which produces intermediates containing radical at the 3-position. The proposed mechanism [36] is shown in 
Table 2 Reduction of furan and dihydrofurans over $\mathrm{Pt} / \mathrm{Al}_{2} \mathrm{O}_{3}$ [36]

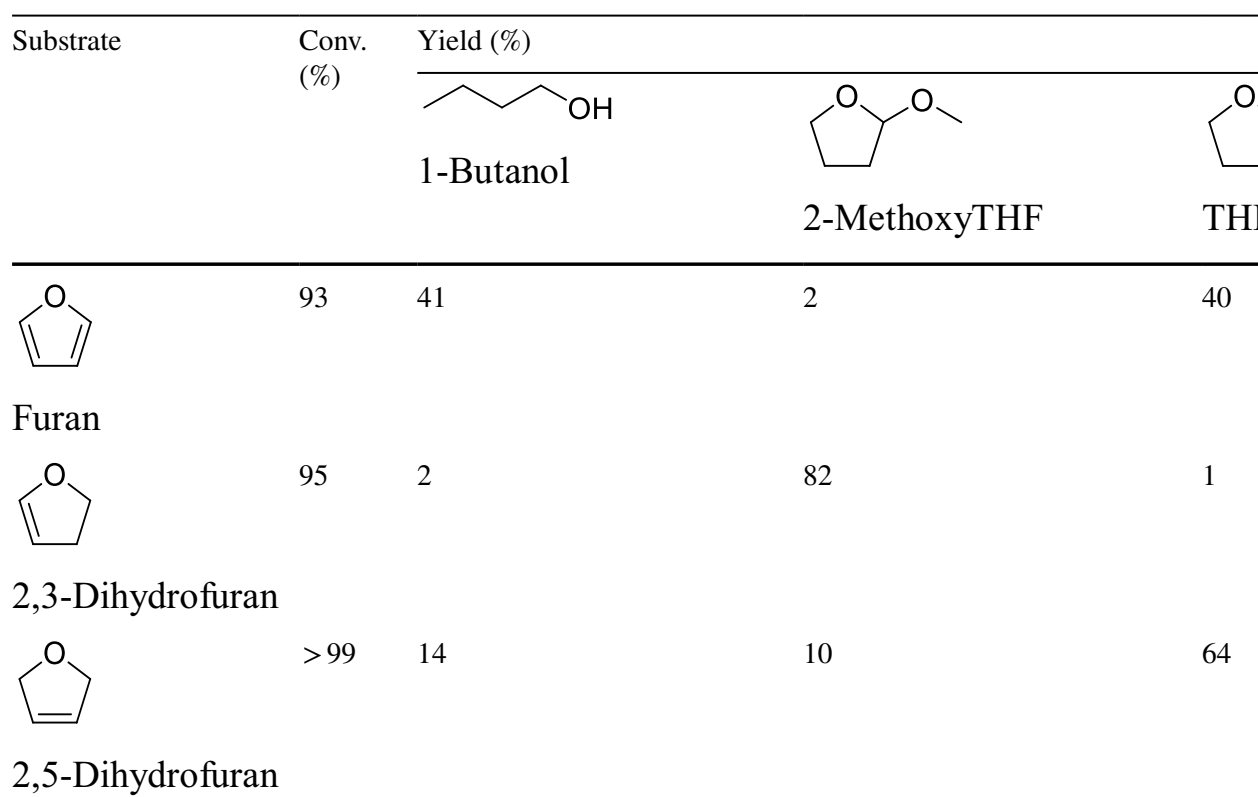

Reaction conditions: $\mathrm{Pt} / \mathrm{Al}_{2} \mathrm{O}_{3}(4 \mathrm{wt} \% \mathrm{Pt}) 50 \mathrm{mg}$, substrate $10 \mathrm{mmol}$, methanol $29 \mathrm{~g}, 1 \mathrm{MPa} \mathrm{Ar}+3 \mathrm{MPa} \mathrm{H}$ $\left(\mathrm{H}_{2}\right.$ was introduced at $\left.373 \mathrm{~K}\right), 373 \mathrm{~K}, 1 \mathrm{~h}$
Fig. 3. FCA molecule is adsorbed on Pt with the carbonyl $\mathrm{C}=\mathrm{O}$ group (step (i)), as suggested by the similar reactivity of FCA and methyl 2-furancarboxylate. One hydrogen atom is added to the 2-position of the furan ring (step (ii)), and the position is directed by the carboxylate group: the carboxylate group is adsorbed on the catalyst surface, and the hydrogen atom on the catalyst surface can more easily approach positions near the carboxylate group. The idea that hydrogen addition occurs at the carbon atom which is bonded to the carboxyl group can explain the higher reactivity of FCA than that of furan-3-carboxylic acid. Next, the $\mathrm{C}-\mathrm{O}$ bond at the 1,2-position is dissociated to give the dienolate species (step (iii)). The dienolate species is protonated and hydrogenated (steps (iv) and (v)) to give 5-HVA. The direction of the position of hydrogen addition and $\mathrm{C}-\mathrm{O}$ bond dissociation by the carboxylate group can be also related to the absence of the product of $\mathrm{C}-\mathrm{O}$ hydrogenolysis at 1,5-position, 2-HVA.

On the other hand, Liu et al. [33] proposed another mechanism based on kinetic modeling and density functional theory (DFT) calculations. The first addition of one hydrogen atom to the furan ring is also suggested to be the kinetically relevant step from the kinetic modeling. The difference is that the FCA molecule is adsorbed with the furan ring and the first hydrogen addition occurs at the 4-position. The carbon atom at the 2-position is still strongly bonded to $\mathrm{Pt}$ surface, and the $\mathrm{C}-\mathrm{O}$ bond is dissociated before addition of hydrogen atom to this carbon atom. One problem of this reaction mechanism is that it cannot be applied to 2,5-dihydrofuran where the carbon atoms in the $\mathrm{C}-\mathrm{O}$ structure cannot be bonded to Pt surface.

The reaction mechanism may be related to that of furfuryl alcohol hydrogenolysis to 1,2- and 1,5-pentanediols, because hydrogenolysis of furfuryl alcohol and FCA has several common features [39-41]. These two substrates are both furans substituted at the 2-position. Both reactions are catalyzed by Pt [42-49]. Both systems cannot open the ring after total hydrogenation (THFCA and tetrahydrofurfuryl alcohol). Alcohols and water are effective solvents for both systems. Although there is no widely accepted mechanism for Pt-catalyzed furfuryl alcohol hydrogenolysis, further mechanistic studies of FCA hydrogenolysis or furfuryl alcohol hydrogenolysis will give useful insights for both the reactions.

When the Pt-catalyzed reaction is applied to FDCA substrate, the product will be 2-hydroxyadipic acid. Wang et al. [50] reported Pt-catalyzed FDCA hydrogenolysis, and actually 2-hydroxyadipic acid was produced over various Pt catalysts. Because the target product of this paper is adipic acid rather than 2-hydroxyadipic acid, the production of 2-hydroxyadipic acid was not investigated in detail (no optimization of reaction conditions). Nevertheless, 2-hydroxyadipic acid yield reaches $73 \%$ which is obtained over Pt/ HZSM-5 catalyst (Eq. 5). 


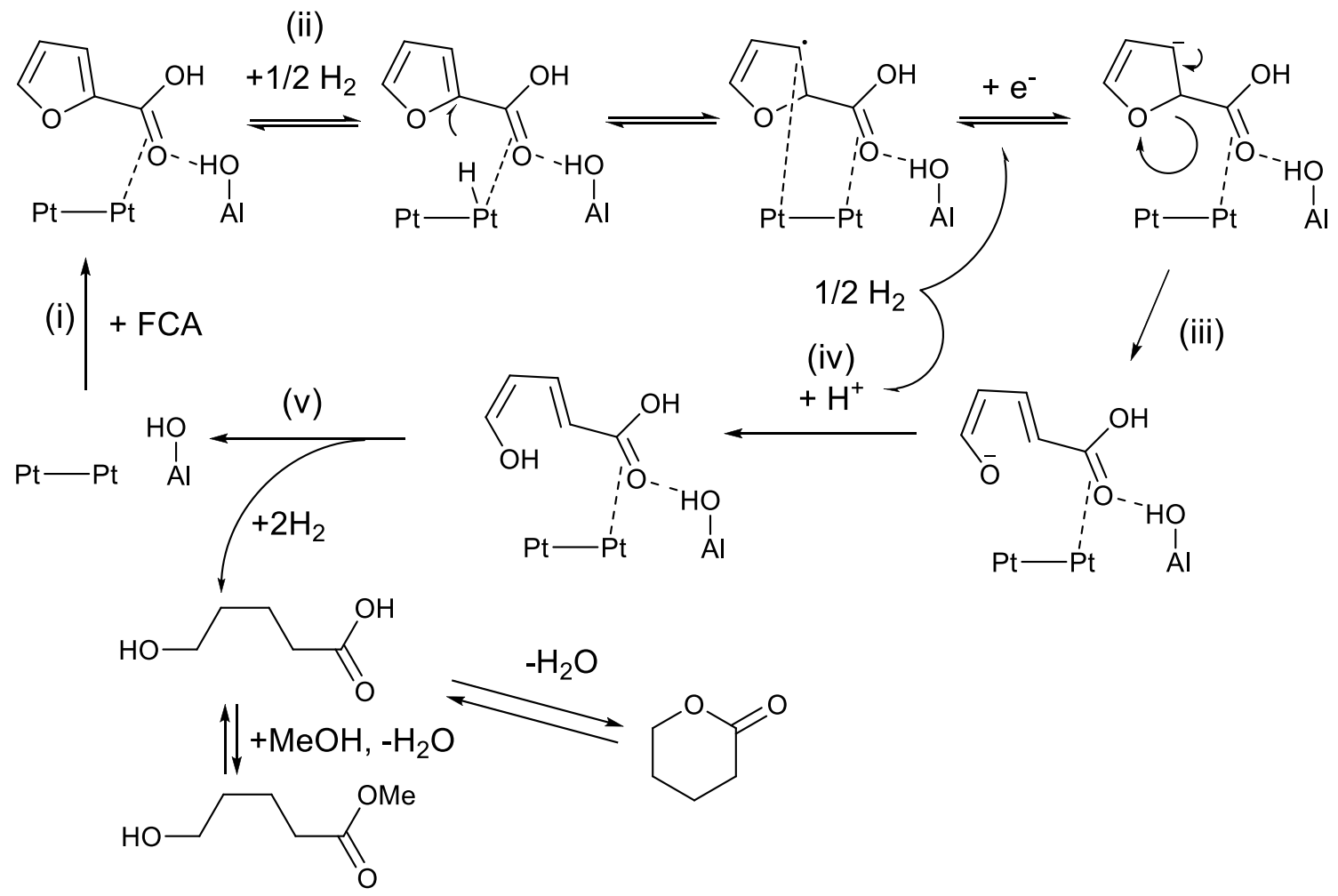

Fig. 3 Proposed reaction mechanism of the reduction of FCA to 5-HVA derivatives over $\mathrm{Pt} / \mathrm{Al}_{2} \mathrm{O}_{3}$ catalyst. Reprinted with permission from Ref. [36] by Royal Society of Chemistry<smiles>O=C(O)c1ccc(C(=O)O)o1</smiles>

$0.1 \mathrm{mmol}$
Pt/HZSM-5(5 wt\% Pt) 20 $\mathrm{mg}, \mathrm{H}_{2} \mathrm{O} 5 \mathrm{~mL}, \mathrm{H}_{2} 3 \mathrm{MPa}$, $473 \mathrm{~K}, 4 \mathrm{~h}$

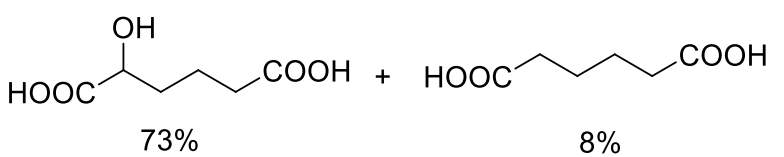

$+$
Our group [51, 52] reported a variant of the Pt-catalyzed $\mathrm{C}-\mathrm{O}$ hydrogenolysis. When the $\mathrm{Pt} / \mathrm{TiO}_{2}$ catalyst is modified with $\mathrm{MoO}_{x}$, the activity in water solvent is much improved, and the main product becomes valeric acid which is the product of the hydrogenolysis of both the $\mathrm{C}-\mathrm{O}$ bonds in the furan ring. The dependence of performance on the Pt and Mo loading amounts shows that the highest activity in valeric acid formation is obtained at around Mo $0.5 \mathrm{wt} \%$ for any Pt loading [52]. With enough amount of catalyst, all Pt-MoO $/ \mathrm{TiO}_{2}$ catalyst with Mo 0.5 $\mathrm{wt} \%$ and $\mathrm{Pt} 1 \mathrm{wt} \%-20 \mathrm{wt} \%$ show similar valeric acid yield of about $60 \%$. However, the stability of Pt-MoO $/ \mathrm{TiO}_{2}$ catalyst is not good, even in comparison with Pt catalysts for 5-HVA production. The Pt- $\mathrm{MoO}_{x} / \mathrm{TiO}_{2}$ catalysts gradually lose activity during reuses regardless of the presence/ absence of regeneration [51]. The necessity of enough amount of catalyst to obtain good valeric acid yield is due to the deactivation. Characterization results with X-ray diffraction (XRD), transmission electron microscopy (TEM), CO adsorption and X-ray absorption fine structure (XAFS) suggest that Mo species are mainly located on the $\mathrm{TiO}_{2}$ support surface as $\mathrm{Mo}(\mathrm{IV})$ species and not on the $\mathrm{Pt}$ metal surface. Pt particles are located on $\mathrm{MoO}_{x} / \mathrm{TiO}_{2}$ and a direct bond between $\mathrm{Pt}$ and Mo is formed at the interface, as detected by extended X-ray absorption fine-structure (EXAFS) spectroscopy. This interface site between $\mathrm{MoO}_{x}$ and Pt is suggested to be catalytically active (Fig. 4) [52]. After catalytic use, the coordination number of $\mathrm{Pt}-\mathrm{Mo}$ direct bond in EXAFS is decreased, which can be connected to the deactivation.

The reaction results of related substrates over the Pt$\mathrm{MoO}_{x} / \mathrm{TiO}_{2}$ catalyst are summarized in Table $3[51,52]$. The 


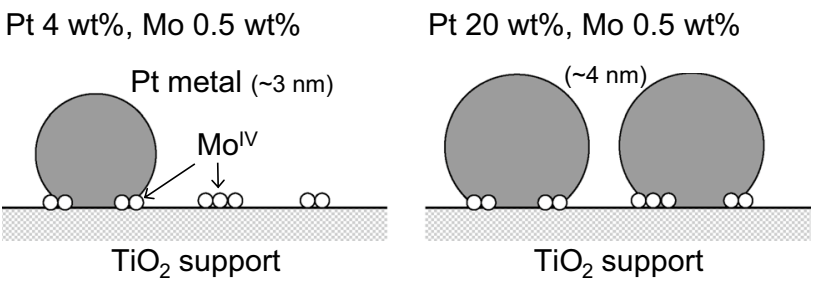

Fig. 4 Model structure of Pt- $\mathrm{MoO}_{x} / \mathrm{TiO}_{2}$ catalysts after reduction. Oxygen atoms in $\mathrm{Mo}^{\mathrm{IV}}$ species are omitted. Reprinted with permission from Ref. [52] by American Chemical Society

hydrogenolysis of FDCA to adipic acid is possible; however, the reactivity and selectivity are much lower than those of FCA to valeric acid. The reactivity of furan-3-carboxylic acid is also very low, and very small amount of deoxygenation product (hydrogenolysis product of the two $\mathrm{C}-\mathrm{O}$ bonds; 2-methylbutyric acid) is formed. This is similar trend to the $\mathrm{Pt} / \mathrm{Al}_{2} \mathrm{O}_{3}$ catalyst for the hydrogenolysis of one $\mathrm{C}-\mathrm{O}$ bond in the furan ring. The reactivity of THFCA is similarly low to the case of $\mathrm{Pt} / \mathrm{Al}_{2} \mathrm{O}_{3}$ catalyst system, and no deoxygenation product (valeric acid) is formed. While small amount of deoxygenation product is formed from furan (butane), such deoxygenation product is hardly formed from dihydrofurans. These similar trends to those of the $\mathrm{Pt} / \mathrm{Al}_{2} \mathrm{O}_{3^{-}}$catalyzed hydrogenolysis system [36] suggest that there are common reaction steps between $\mathrm{Pt}-\mathrm{MoO}_{x} / \mathrm{TiO}_{2}-$ and $\mathrm{Pt} /$ $\mathrm{Al}_{2} \mathrm{O}_{3}$-catalyzed systems. We proposed a reaction mechanism for $\mathrm{Pt}-\mathrm{MoO}_{x} / \mathrm{TiO}_{2}$-catalyzed hydrodeoxygenation (Fig. 5) [52]. This is composed of FCA coordination on Pt site (same as step (i) in Fig. 3), addition of one hydrogen atom to the 3-position of the furan ring (same as step (ii) in Fig. 3), C-O dissociation promoted by Mo species (similar to step (iii) in Fig. 3, the difference is the involvement of Mo species), further $\mathrm{C}-\mathrm{O}$ dissociation by the reduction with the Mo(IV) species to pentadienoic acid and Mo(VI) species, and hydrogenation of pentadienoic acid to valeric acid. The $\mathrm{Mo}(\mathrm{VI})$ species is also reduced with hydrogen to Mo(IV).

\section{Hydrodeoxygenation of Tetrahydrofurancarboxylic Acids}

One-step hydrodeoxygenation of FCA or FDCA is a difficult reaction; the $\mathrm{Pt}-\mathrm{MoO}_{x} / \mathrm{TiO}_{2}$ catalyst system discussed above has problems of low yield (especially for FDCA to adipic acid) and low stability. The multistep method composed of hydrogenation of furan ring and hydrodeoxygenation of the saturated tetrahydrofuran ring is another approach to the deoxygenation of FCA or FDCA. Typically, hydrodeoxygenation ( $\mathrm{C}-\mathrm{O}$ hydrogenolysis) of alcohols or ether can proceed with the combination of metal and strong acid catalysts via E1 type acid-catalyzed dehydration (or de-alkoxylation in the case of ethers) and metal-catalyzed hydrogenation [53, 54]. However, the dissociation of $\mathrm{C}-\mathrm{O}$ bond at $\alpha$-position of carbonyl groups such as 2-position of carboxylic acids is difficult because of the electron-withdrawing effect of the carbonyl group, while $\mathrm{C}-\mathrm{H}$ bond is easily dissociated at this position. Effective systems for the $\mathrm{C}-\mathrm{O}$ dissociation of $\alpha$-functionalized carboxylic acids such as tetrahydrofurancarboxylic acids and lactic acid $[55,56]$ are very limited.

Wang et al. [50] reported $\mathrm{Pt} / \mathrm{Nb}_{2} \mathrm{O}_{5} \bullet x \mathrm{H}_{2} \mathrm{O}$ catalyst for the production of adipic acid from FDCA. Niobium oxides are well known solid acids which can work in water solvent [57]. In water solvent under $3 \mathrm{MPa} \mathrm{H}_{2}$ at $473 \mathrm{~K}, \mathrm{Pt} / \mathrm{Nb}_{2} \mathrm{O}_{5} \bullet x \mathrm{H}_{2} \mathrm{O}$ catalyst converts FDCA first to THFDCA. Some amount of 2-hydroxyadipic acid is probably formed via the ring-opening hydrogenolysis discussed in the above section. THFDCA is

Table 3 Reduction of various substrates over $\mathrm{Pt}-\mathrm{MoO}_{x} / \mathrm{TiO}_{2}$ [51, 52]

\begin{tabular}{lll}
\hline Substrate & Conv. (\%) & Products (yield (\%)) \\
\hline FCA & 97 & Valeric acid (51), THFCA (4), DVL (5), 5-HVA (7), 5-oxyvaleric acid (9) \\
FCA $^{\text {a }}$ & $>99$ & Valeric acid (61), THFCA (2), DVL (3), 5-HVA (3), 5-oxyvaleric acid (5) \\
FDCA $^{\text {b }}$ & $>99$ & Adipic acid (5), THFDCA (20) \\
FDCA $^{\text {c }}$ & $>99$ & Adipic acid (21), THFDCA (1) \\
THFCA & 18 & 1,5-Pentanediol (4), DVL (1) \\
3-Furancarboxylic acid & 9 & 2-Methylbutyric acid (3), $\gamma$-valerolactone (3) \\
Furan & $>99$ & 1-Butanol (35), THF (15), Butane (9) \\
2,3-Dihydrofuran & $>99$ & THF (47), 1-butanol (20), 1,4-butanediol (14) \\
2,5-Dihydrofuran & $>99$ & THF (46), 1-butanol (24), 1,4-butanediol (14), butane (1)
\end{tabular}

Reaction conditions: $\mathrm{Pt}-\mathrm{MoO}_{x} / \mathrm{TiO}_{2}(4 \mathrm{wt} \% \mathrm{Pt}, 0.5 \mathrm{wt} \% \mathrm{Mo}) 0.1 \mathrm{~g}$, substrate $10 \mathrm{mmol}$, water $19 \mathrm{~g}, \mathrm{H}_{2} 1.5 \mathrm{MPa}, 413 \mathrm{~K}, 4 \mathrm{~h}$

${ }^{\mathrm{a}} \mathrm{Pt}-\mathrm{MoO}_{x} / \mathrm{TiO}_{2}(20 \mathrm{wt} \% \mathrm{Pt}, 0.5 \mathrm{wt} \% \mathrm{Mo}) 0.1 \mathrm{~g}$

${ }^{\mathrm{b}} \mathrm{FDCA} 5 \mathrm{mmol}$

${ }^{c}$ FDCA 5 mmol, $473 \mathrm{~K}$. FCA=2-furancarboxylic acid, THFCA=tetrahydrofuran-2-carboxylic acid, DVL= $\delta$-valerolactone, HVA =hydroxyvaleric acid, FDCA =2,5-furandicarboxylic acid, THFDCA = tetrahydrofuran-2,5-dicarboxylic acid 


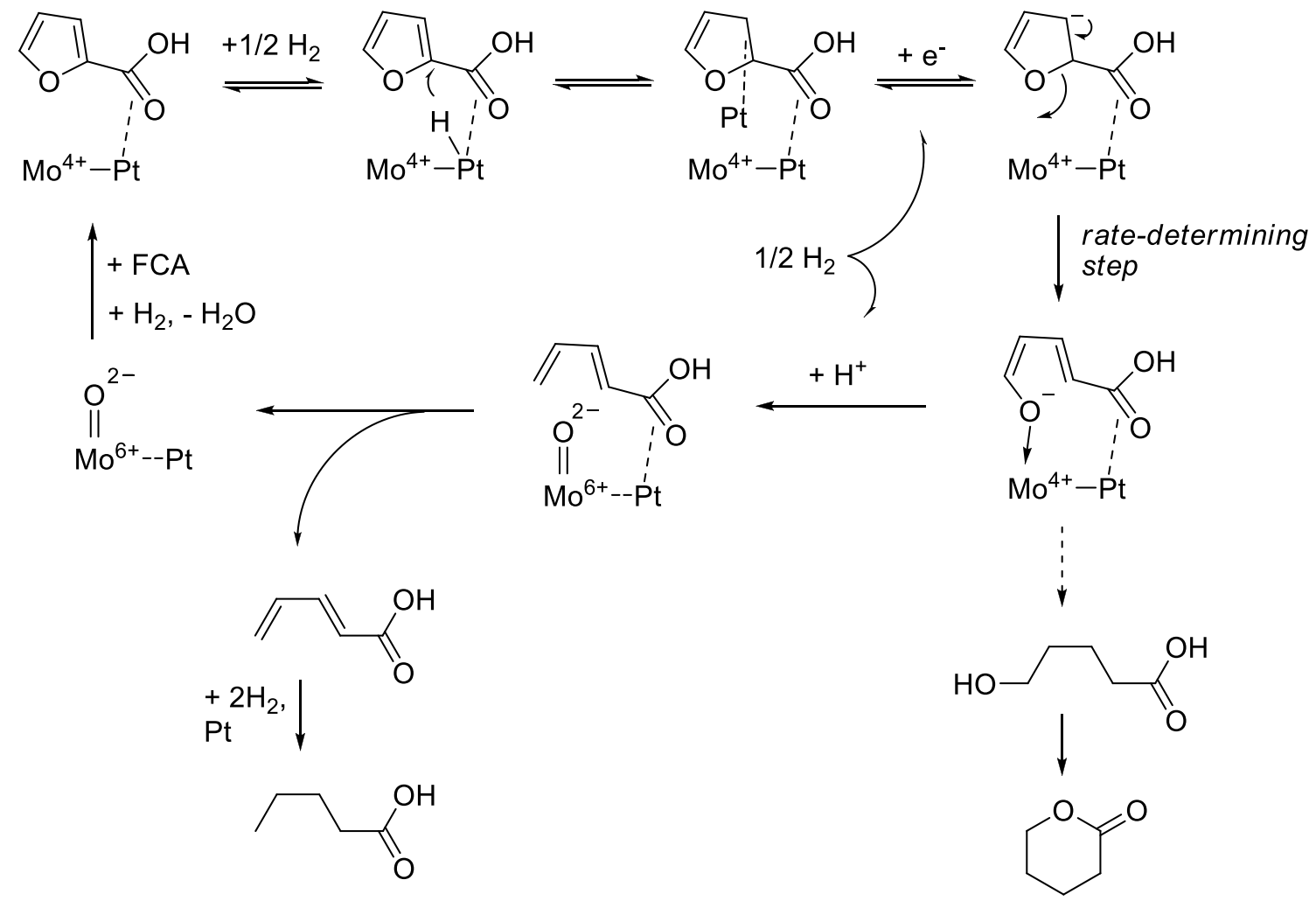

Fig. 5 Proposed reaction mechanism of FCA reduction to valeric acid over Pt- $\mathrm{MoO}_{x} / \mathrm{TiO}_{2}$ catalyst. Reprinted with permission from Ref. [52] by American Chemical Society

then converted to 2-hydroxyadipic acid by $\mathrm{C}-\mathrm{O}$ hydrogenolysis over metal ( $\mathrm{Pt}$ ) and acid (niobium oxide). 2-Hydroxyadipic acid produced directly or indirectly from FDCA is further converted to adipic acid also by $\mathrm{C}-\mathrm{O}$ hydrogenolysis. These reactions proceed in one pot. However, there is large loss of carbon balance, and the maximum obtained yield of adipic acid is $38 \%$. Fu et al. [58] have very recently reported the reduction of FCA with the combination catalysts of $\mathrm{Pd} / \mathrm{C}$ and rare earth triflates as Lewis acids in acetic acid solvent. The authors had expected that THFCA first formed by hydrogenation of FCA over Pd would suffer ring opening by addition of acetic acid and then lose an oxygen atom by $\mathrm{C}-\mathrm{O}$ hydrogenolysis to 5 -acetoxyvaleric acid. However, the main product actually observed was the diester of 1,4-butanediol (maximum $83 \%$ yield). The reaction time dependence shows that THFCA produced first is converted to THF via decarbonylation (stoichiometric amount of $\mathrm{CO}$ is detected) and hydrogenation, and then the ring opening of THF occurs (Eq. 6).
Vlachos et al. [59-61] have intensively investigated the hydrogenolysis of THFDCA to adipic acid with the help of iodide ion. The reaction was first reported by Boussie et al. [31] in a patent using the combination of $\mathrm{Pd}$ and $\mathrm{HI}$ catalysts. The iodide ion dissociates the $\mathrm{C}-\mathrm{O}$ bond by $\mathrm{S}_{\mathrm{N}} 2$ mechanism, and then the $\mathrm{C}-\mathrm{I}$ bond is reduced to produce the $\mathrm{C}-\mathrm{H}$ bond and to regenerate iodide. Vlachos et al. [59] clarified that $\mathrm{Pd}$ catalyst is not necessary in the $\mathrm{C}-\mathrm{O}$ hydrogenolysis steps and that the combination of solid acid and alkali iodide can be used instead of HI, which is a toxic and very corrosive reagent $[60$, $61]$. The adipic acid yield reached $87 \%$, which is obtained with the combination of Nafion and LiI (Eq. 7) [60].<smiles>O=C(O)c1ccco1</smiles> 


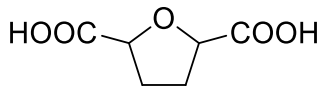

$0.15 \mathrm{~g}$
Nafion $5.4 \mathrm{~g}\left(0.3 \mathrm{M}\right.$ effective $\left.\mathrm{H}^{+}\right)$, Lil $0.6 \mathrm{~g}(0.3 \mathrm{M})$, propionic acid $15 \mathrm{~mL}, \mathrm{H}_{2} 3.4 \mathrm{MPa}, 433 \mathrm{~K}, 2 \mathrm{~h}$<smiles>O=C(O)CCCCC(=O)O</smiles>

$87 \%$
$\mathrm{C}-\mathrm{O}$ hydrogenolysis of saturated compounds is known to be catalyzed by bimetallic catalysts composed of noble metal and groups 6-7 metal oxide such as $\mathrm{Rh}-\mathrm{MoO}_{x}, \mathrm{Rh}-\mathrm{ReO}$, $\mathrm{Ir}-\mathrm{ReO}_{x}$ and $\mathrm{Pt}-\mathrm{WO}_{x}$ [62-68]. In these catalysts, partially reduced metal oxide directly interacts with noble metal
[70-75]. However, the ratio is still lower than 1 even at low conversion level over $\mathrm{Rh}-\mathrm{WO}_{x} / \mathrm{SiO}_{2}$ catalyst. At higher conversion level, the ratio is further decreased probably because of the successive hydrogenation of the carboxyl/lactone group in DVL and 5-HVA. The reported run with the highest yield of $\mathrm{DVL}+5$-HVA over $\mathrm{Rh}-\mathrm{WO}_{x} / \mathrm{SiO}_{2}$ is shown as Eq. (9).

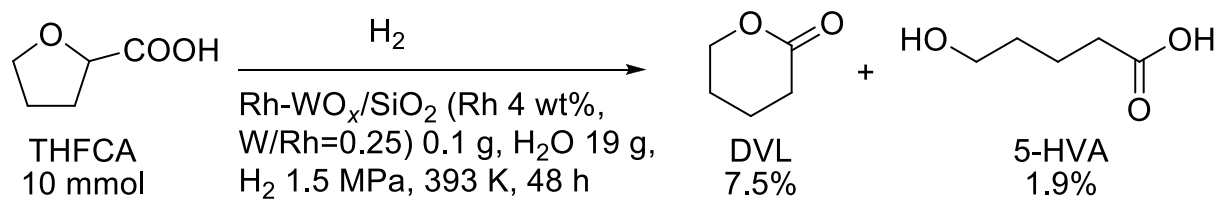

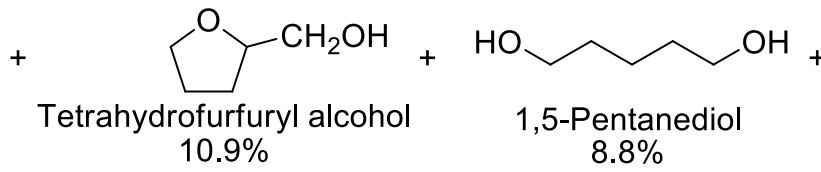

surface, and the interface site becomes catalytically active. The $\mathrm{C}-\mathrm{O}$ bond neighboring to the terminal $-\mathrm{CH}_{2} \mathrm{OH}$ group is selectively dissociated, as exemplified by the transformation of tetrahydrofurfuryl alcohol to 1,5-pentanediol (Eq. 8). If the same position (1,2-position of the tetrahydrofuran ring) in THFCA is dissociated, 5-HVA will be produced.

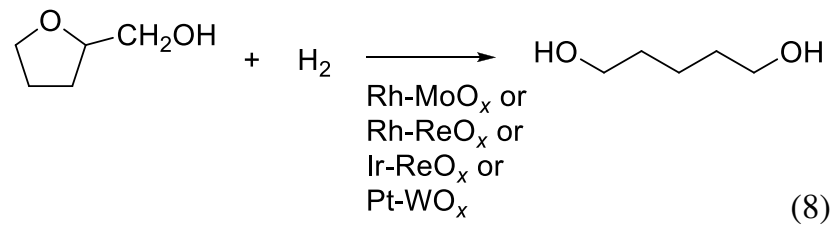

However, these catalysts also have activity in hydrogenation of carboxylic acids. Our group [69] tested various $\mathrm{SiO}_{2}$-supported bimetallic catalysts composed of noble metal $(\mathrm{Rh}, \mathrm{Pd}, \mathrm{Pt}, \mathrm{Ru}$ and $\mathrm{Ir})$ and groups 6-7 metal oxide $\left(\mathrm{MoO}_{x}\right.$, $\mathrm{ReO}_{x}$ and $\mathrm{WO}_{x}$ ) to $\mathrm{C}-\mathrm{O}$ hydrogenolysis of THFCA. $\mathrm{SiO}_{2}$ is a typical support for these bimetallic catalysts because the interaction between $\mathrm{SiO}_{2}$ and the supported metal or metal oxide is weak and does not interfere with the formation of interface site between the supported species. The combination of $\mathrm{Rh}$ and $\mathrm{WO}_{x}$ shows the highest ratio of formation amount of $\mathrm{C}-\mathrm{O}$ hydrogenolysis products (DVL +5-HVA) to that of carboxylic acid hydrogenation products (tetrahydrofurfuryl alcohol, 1,5-pentanediol and 1-pentanol). $\mathrm{MoO}_{x}$ and $\mathrm{ReO}_{x}$ species are known to have activity or promotion ability in carboxylic acid hydrogenation, especially when combined with $\mathrm{Rh}$, and these characters lower the formation amount ratio of $\mathrm{C}-\mathrm{O}$ hydrogenolysis products to carboxylic acid hydrogenation products

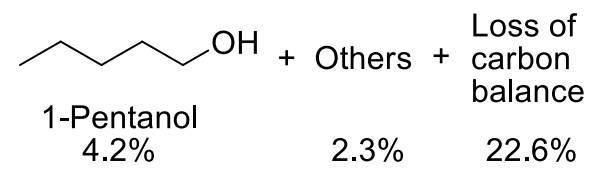

\section{Comparison with Systems Using Other Biomass-Derived Substrates}

Among the potential reduction products from FCA or FDCA with retention of the carboxyl groups, adipic acid is by far the most used chemical in industry. Adipic acid is currently manufactured from petroleum by hydrogenation of benzene to cyclohexane, aerobic catalytic oxidation of cyclohexane to ketone-alcohol (K-A) oil, and oxidation of K-A oil to adipic acid with nitric acid as the oxidant [76]. Adipic acid is mainly used as a monomer of polyamide, and the global production amount is in the order of $10^{6} \mathrm{t} / \mathrm{year}$. Because of the enormous use of petroleum, hydrogen and nitric acid in the current process, the production of adipic acid from biomass has been intensively investigated in these days. Other production methods of adipic acid from biomass include (i) conversion of hydrocarbons produced by BTL (biomass to liquid; combination of biomass gasification and Fischer-Tropsch synthesis) [77] in petrochemical processes, (ii) production of K-A oil by reduction of biomass pyrolysis oil (bio-oil) [78-83], (iii) direct production of adipic acid by fermentation [84], (iv) hydrodeoxygenation of sugar acids produced by oxidation of sugars [85-92], (v) extension of carbon chain of C5 biomass-derived platform chemicals such as $\gamma$-valerolactone by hydroformylation or carboxylation [93-96], and (vi) oxidative cleavage of 1,2-difunctionalized cyclohexanes produced by reduction of bio-oil [97-100]. Low yield from raw biomass (methods (i), (ii), (iii) and (vi)) and large number of steps (methods (i), (ii), 
(v) and (vi)) are the main problems of these methods. The FDCA-based systems are highly competitive to these systems except (iv) in these views. The sugar-acid-based system (iv) has several similarities to the FDCA-based systems: hexoses such as glucose and cellulose are the raw biomass; the consumption amount of hydrogen in the process is the same (4 equiv.), and the whole process is composed of two or three steps from sugars. The advantages of the FDCAbased systems are that FDCA can be more easily separated and handled than sugar acids and that large-scale production of FDCA will be realized because FDCA itself can be used as a monomer of PEF resin.

5 -HVA is an $\omega$-hydroxycarboxylic acid and can be a monomer of resin [101]. The conventional production method of 5-HVA or DVL is the oxidation or dehydrogenation of 1,5-pentanediol [102]. 1,5-Pentanediol can be produced from glutaric acid [103], which is a by-product of adipic acid [104], and 1,5-pentanediol can be also produced from biomass via furfural [39-41]. Another biomass-based production method of 5-HVA or DVL is Baeyer-Villiger oxidation of cyclopentanone [105-108], which can be also produced by reduction of furfural involving Piancatelli rearrangement $[4-7,109]$. Production of 1,5-pentanediol from furfural requires larger amount of hydrogen (4 equiv.) than the FCA reduction to 5-HVA or DVL (3 equiv.). Baeyer-Villiger oxidation requires a peracid or $\mathrm{H}_{2} \mathrm{O}_{2}$ as a stoichiometric oxidant. The FCA-based method has superiority to these two methods in view of the reactant cost. The product from FDCA in the same type of reaction, 2-hydroxyadipic acid, has not been regarded as the target of large-scale productions.

Valeric acid is expected to be used in the ester form as fuel additives [110-112]. The main interest in the production of valeric acid or valerates focuses on the production from levulinic acid. Levulinic acid is a very important platform chemical synthesized from sugars or lignocellulose by the treatment with hot acidic water $[113,114] . \gamma$-Valerolactone, which is formed by hydrogenation and dehydration of levulinic acid, is an intermediate of valeric acid production. The production of $\gamma$-valerolactone from levulinic acid is relatively easy over simple metal catalysts, and the production of valeric acid from $\gamma$-valerolactone uses the combination of metal and acid catalysts. Recently, one-pot systems using the combination of metal and acid catalysts have been reported with excellent yields $(>90 \%)$ of valeric acid or valerate from levulinic acid $[111,112,115]$. The conversion requires two equiv. of hydrogen, and the production of levulinic acid from biomass does not require expensive reagent. The FCA-based route is not advantageous to levulinic acid-based method in view of the reactant cost. Strong merit is necessary to select the FCA-based route, for example, the applicability of the gas-phase flow systems.

\section{Conclusions and Outlook}

2-Furancarboxylic acid (FCA) and 2,5-furandicarboxylic acid (FDCA) are stable oxidation products of furfural and 5-hydroxymethylfurfural (HMF), which are very important and versatile platform chemicals in lignocellulose conversions, and therefore, FCA and FDCA can be also regarded as platform chemicals. In particular, because FDCA itself has been regarded as a monomer of a promising biomassderived resin polyethylene 2,5-furandicarboxylate (PEF), large amount of inexpensive FDCA with high purity will be available when PEF is industrialized in a large scale. The important target products from FCA and FDCA are carboxylic acids because the reduction products of carboxyl groups in FCA and FDCA can be directly produced from furfural or HMF. In particular, 5-hydroxyvaleric acid (5-HVA) and adipic acid, which are the reduction products from FCA and FDCA, respectively, are promising targets in view of the importance of products and the comparison with other production methods. 5-HVA or its derivatives such as $\delta$-valerolactone (DVL) and 5-hydroxyvalerates are produced from FCA over simple Pt catalysts. Adipic acid, which is a very important monomer in industry, is produced from FDCA via one-pot reaction or two-step method. One-pot reaction uses the combination of $\mathrm{Pt}$ with modifier $\left(\mathrm{MoO}_{x}\right)$ or strong acid (niobium oxide). The yield of adipic acid is low at present. Two-step method is composed of Pd-catalyzed hydrogenation to tetrahydrofuran-2,5-dicarboxylic acid (THFDCA) and hydrodeoxygenation with iodide ion. Good yield $(>85 \%)$ is obtained, although the capital cost might be higher for the two-step method. Other potentially useful reduction products from FCA and FDCA include valeric acid and 2-hydroxyadipic acid.

The studies for the reduction of FCA or FDCA with retention of the carboxyl groups have been carried out only in very recent days (published in 2010 or later) except an old report with $\mathrm{PtO}_{2}$ (Adams catalyst) and reports for simple ring-hydrogenation systems. The number of research groups engaged in the studies of FCA or FDCA reductions is limited at present, considering that furfural and HMF reductions have been very intensively investigated by many research groups. The information of the reaction mechanisms and the structure of active centers of the catalysts is also limited, especially for the Pt-catalyzed $\mathrm{C}-\mathrm{O}$ hydrogenolysis of the furan ring. We hope that more researchers will be interested in the FCA or FDCA conversions, uncovering the whole chemistry and developing more efficient systems.

Acknowledgements This work was financially supported by New Energy and Industrial Technology Development Organization (NEDO) under the program of Extensive Support for Young Promising Researchers. 
Open Access This article is licensed under a Creative Commons Attribution 4.0 International License, which permits use, sharing, adaptation, distribution and reproduction in any medium or format, as long as you give appropriate credit to the original author(s) and the source, provide a link to the Creative Commons licence, and indicate if changes were made. The images or other third party material in this article are included in the article's Creative Commons licence, unless indicated otherwise in a credit line to the material. If material is not included in the article's Creative Commons licence and your intended use is not permitted by statutory regulation or exceeds the permitted use, you will need to obtain permission directly from the copyright holder. To view a copy of this licence, visit http://creativecommons.org/licenses/by/4.0/.

\section{References}

1. Bozell JJ, Petersen GR (2010) Technology development for the production of biobased products from biorefinery carbohydrates - the US Department of Energy's “Top 10" revisited. Green Chem 12(4):539-554

2. Mika LT, Cséfalvay E, Németh Á (2018) Catalytic conversion of carbohydrates to initial platform chemicals: chemistry and sustainability. Chem Rev 118(2):505-613

3. Millán GG, Hellsten S, Llorca J et al (2019) Recent advances in the catalytic production of platform chemicals from holocellulosic biomass. ChemCatChem 11(8):2022-2042

4. Nakagawa Y, Tamura M, Tomishige K (2013) Catalytic reduction of biomass-derived furanic compounds with hydrogen. ACS Catal 3(12):2655-2668

5. Caes BR, Teixeira RE, Knapp KG et al (2015) Biomass to furanics: renewable routes to chemicals and fuels. ACS Sustain Chem Eng 3(11):2591-2605

6. Chen S, Wojcieszak R, Dumeignil F et al (2018) How catalysts and experimental conditions determine the selective hydroconversion of furfural and 5-hydroxymethylfurfural. Chem Rev 118(22):11023-11117

7. Paone CXE, Rodríguez-Padrón D, Luque R et al (2020) Recent catalytic routes for the preparation and the upgrading of biomass derived furfural and 5-hydroxymethylfurfural. Chem Soc Rev 49(13):4273-4306

8. Yang ZR, Zhang J, Qian G et al (2020) Production of biomass derived monomers through catalytic conversion of furfural and hydroxymethylfurfural. Green Chem Eng 62(4):566-606

9. Gupta S, Alam MI, Khan TS et al (2019) Mechanistic approaches toward rational design of a heterogeneous catalyst for ring-opening and deoxygenation of biomass-derived cyclic compounds. ACS Sustain Chem Eng 7(12):10165-10181

10. Iriondo A, Agirre I, Viar N et al (2020) Value-added bio-chemicals commodities from catalytic conversion of biomass derived furan-compounds. Catalysts 10(8):895

11. Sajid M, Zhao XB, Liu DH (2018) Production of 2,5-furandicarboxylic acid (FDCA) from 5-hydroxymethylfurfural (HMF): recent progress focusing on the chemical-catalytic routes. Green Chem 20(24):5427-5453

12. Arias PL, Cecilia JA, Gandarias I et al (2020) Oxidation of lignocellulosic platform molecules to value-added chemicals using heterogeneous catalytic technologies. Catal Sci Technol 10(9):2721-2757

13. Zhou CM, Deng WP, Wan XY et al (2015) Functionalized carbon nanotubes for biomass conversion: the base-free aerobic oxidation of 5-hydroxymethylfurfural to 2,5-furandicarboxylic acid over platinum supported on a carbon nanotube catalyst. ChemCatChem 7(18):2853-2863
14. Chen H, Shen JS, Chen KQ et al (2018) Atomic layer deposition of Pt nanoparticles on low surface area zirconium oxide for the efficient base-free oxidation of 5-hydroxymethylfurfural to 2,5-furandicarboxylic acid. Appl Catal A 555:98-107

15. Zhou CM, Shi WR, Wan XY et al (2019) Oxidation of 5-hydroxymethylfurfural over a magnetic iron oxide decorated rGO supporting Pt nanocatalyst. Catal Today 330:92-100

16. Gupta NK, Nishimura S, Takagaki A et al (2011) Hydrotalcitesupported gold-nanoparticle-catalyzed highly efficient base-free aqueous oxidation of 5-hydroxymethylfurfural into 2,5-furandicarboxylic acid under atmospheric oxygen pressure. Green Chem 13(4):824-827

17. Wan WY, Zhou CM, Chen JS et al (2014) Base-free aerobic oxidation of 5-hydroxymethyl-furfural to 2,5-furandicarboxylic acid in water catalyzed by functionalized carbon nanotube-supported Au-Pd alloy nanoparticles. ACS Catal 4(7):2175-2185

18. Douthwaite M, Huang X, Iqbal S et al (2017) The controlled catalytic oxidation of furfural to furoic acid using $\mathrm{AuPd} / \mathrm{Mg}(\mathrm{OH})_{2}$. Catal Sci Technol 7(22):5284-5293

19. Ferraz CP, Zieliński M, Pietrowski M et al (2018) Influence of support basic sites in green oxidation of biobased substrates using Au-promoted catalysts. ACS Sustain Chem Eng 6(12):16332-16340

20. Bonincontro D, Lolli A, Villa A et al (2019) AuPd-nNiO as an effective catalyst for the base-free oxidation of HMF under mild reaction conditions. Green Chem 21(15):4090-4099

21. Cai CL, Xu JG, Wang HY et al (2020) Homogeneous basefree oxidation of 5-hydroxymethyfufural to 2,5-furandicarboxylic acid over $\mathrm{Au} / \mathrm{Mg}(\mathrm{OH})_{2}$ catalysts. ChemistrySelect 5(41):12785-12790

22. Pichler CM, Al-Shaal MG, Gu D et al (2018) Ruthenium supported on high-surface-area zirconia as an efficient catalyst for the base-free oxidation of 5-hydroxymethylfurfural to 2,5-furandicarboxylic acid. Chemsuschem 11(13):2083-2090

23. Zuo XB, Venkitasubramanian P, Busch DH et al (2016) Optimization of $\mathrm{Co} / \mathrm{Mn} / \mathrm{Br}$-catalyzed oxidation of 5-hydroxymethylfurfural to enhance 2,5-furandicarboxylic acid yield and minimize substrate burning. ACS Sustain Chem Eng 4(7):3659-3668

24. Hayashi E, Komanoya T, Kamata K et al (2017) Heterogeneously-catalyzed aerobic oxidation of 5-hydroxymethylfurfural to 2,5-furandicarboxylic acid with $\mathrm{MnO}_{2}$. Chemsuschem 10(4):654-658

25. Hayashi E, Yamaguchi Y, Kamata K et al (2019) Effect of $\mathrm{MnO}_{2}$ crystal structure on aerobic oxidation of 5-hydroxymethylfurfural to 2,5-furandicarboxylic acid. J Am Chem Soc 141(2):890-900

26. Sousa AF, Vilela C, Fonseca AC et al (2015) Biobased polyesters and other polymers from 2,5-furandicarboxylic acid: a tribute to furan excellency. Polym Chem 6(33):5961-5983

27. Papageorgiou GZ, Papageorgiou DG, Terzopoulou Z et al (2016) Production of bio-based 2,5-furan dicarboxylate polyesters: recent progress and critical aspects in their synthesis and thermal properties. Eur Polym J 83:202-229

28. Loos K, Zhang RY, Pereira I et al (2020) A perspective on PEF synthesis, properties, and end-life. Front Chem 8:585

29. Luneau M, Lim JS, Patel DA et al (2020) Guidelines to achieving high selectivity for the hydrogenation of $\alpha, \beta$-unsaturated aldehydes with bimetallic and dilute alloy catalysts: a review. Chem Rev 120(23):12834-12872

30. Maris M, Huck WR, Mallat T et al (2003) Palladium-catalyzed asymmetric hydrogenation of furan carboxylic acids. J Catal 219:52-58

31. Boussie TR, Dias EL, Fresco ZM et al (2010) Production of adipic acid and derivatives from carbohydrate-containing materials. U.S. Patent 0317822 
32. Zaytsev AV, Pickles JE, Harnor SJ (2016) Concise syntheses of bridged morpholines. RSC Adv 6(59):53955-53957

33. Sun QH, Wang S, Liu HC (2019) Selective hydrogenolysis of $\alpha-\mathrm{C}-\mathrm{O}$ bond in biomass-derived 2-furancarboxylic acid to 5-hydroxyvaleric acid on supported Pt catalysts at near-ambient temperature. ACS Catal 9(12):11413-11425

34. Besson M, Pinel C (2003) Diastereoselective heterogeneous catalytic hydrogenation of aromatic or heteraromatic compounds. Top Catal 25(1-4):43-61

35. Zhang XB, Chen LN, Li YJ et al (2019) Palladium NPs supported on sulfonic acid functionalized metal-organic frameworks as catalysts for biomass cascade reactions. Dalton Trans 48(17):5515-5519

36. Asano T, Takagi H, Nakagawa Y et al (2019) Selective hydrogenolysis of 2-furancarboxylic acid to 5-hydroxyvaleric acid derivatives over supported platinum catalysts. Green Chem 21(22):6133-6145

37. Maris M, Mallat T, Orglmeister E et al (2004) On the role of modifier structure in the palladium-catalyzed enantioselective hydrogenation of furan-2-carboxylic acid. J Mol Catal A 219:371-376

38. Studer M, Wedemeyer-Exl C, Spindler F et al (2000) Enantioselective homogeneous hydrogenation of monosubstituted pyridines and furans. Monatschefte Chem 131:1335-1343

39. Nakagawa Y, Tamura M, Tomishige K (2015) Catalytic conversions of furfural to pentanediols. Catal Surv Asia 19:249-256

40. Liu SB, Tamura M, Nakagawa Y et al (2018) Catalytic transformations of furfural and its derived compounds into pentanediols. World Scientific, Singapore, pp 91-109

41. Enjamuri N, Darbha S (2020) Solid catalysts for conversion of furfural and its derivatives to alkanediols. Catal Rev Sci Eng 62(4):566-606

42. Smith HA, Fuzek JF (1949) Catalytic hydrogenation of furan and substituted furans on platinum. J Am Chem Soc 71(2):415-419

43. Xu WJ, Wang HF, Liu XH et al (2011) Direct catalytic conversion of furfural to 1,5-pentanediol by hydrogenolysis of the furan ring under mild conditions over $\mathrm{Pt} / \mathrm{Co}_{2} \mathrm{AlO}_{4}$ catalyst. Chem Commun 47(13):3924-3926

44. Mizugaki T, Yamakawa T, Nagatsu Y et al (2014) Direct transformation of furfural to 1,2-pentanediol using a hydrotalcitesupported platinum nanoparticle catalyst. ACS Sustain Chem Eng 2(10):2243-2247

45. Ma RF, Wu XP, Tong $\mathrm{T}$ et al (2017) The critical role of water in the ring opening of furfural alcohol to 1,2-pentanediol. ACS Catal 7(1):333-337

46. Tong T, Xia QN, Liu XH et al (2017) Direct hydrogenolysis of biomass-derived furans over $\mathrm{Pt} / \mathrm{CeO}_{2}$ catalyst with high activity and stability. Catal Commun 101:129-133

47. Tong T, Liu XH, Guo Y et al (2018) The critical role of $\mathrm{CeO}_{2}$ crystal-plane in controlling Pt chemical states on the hydrogenolysis of furfuryl alcohol to 1,2-pentanediol. J Catal 365:420-428

48. Yeh JY, Matsagar BM, Chen SS et al (2020) Synergistic effects of Pt-embedded, MIL-53-derived catalysts $\left(\mathrm{Pt} @ \mathrm{Al}_{2} \mathrm{O}_{3}\right)$ and $\mathrm{NaBH}_{4}$ for water-mediated hydrogenolysis of biomass-derived furfural to 1,5-pentanediol at near-ambient temperature. J Catal 390:46-56

49. Zhu YR, Zhao WF, Zhang J et al (2020) Selective activation of $\mathrm{C}-\mathrm{OH}, \mathrm{C}-\mathrm{O}-\mathrm{C}$, or $\mathrm{C}=\mathrm{C}$ in furfuryl alcohol by engineered Pt sites supported on layered double oxides. ACS Catal 10(15):8032-8041

50. Wei LF, Zhang JX, Deng WP et al (2019) Catalytic transformation of 2,5-furandicarboxylic acid to adipic acid over niobic acidsupported Pt nanoparticles. Chem Commun 55(55):8013-8016

51. Asano T, Tamura M, Nakagawa Y et al (2016) Selective hydrodeoxygenation of 2-furancarboxylic acid to valeric acid over molybdenum-oxide-modified platinum catalyst. ACS Sustain Chem Eng 4(12):6253-6257
52. Asano T, Nakagawa Y, Tamura M et al (2019) Structure and mechanism of titania-supported platinum-molybdenum catalyst for hydrodeoxygenation of 2-furancarboxylic acid to valeric acid. ACS Sustain Chem Eng 7(10):9601-9612

53. Nakagawa Y, Liu SB, Tamura M et al (2015) Catalytic total hydrodeoxygenation of biomass-derived polyfunctionalized substrates to alkanes. Chemsuschem 8(7):1114-1132

54. Luo WH, Cao WX, Bruijnincx PCA et al (2019) Zeolitesupported metal catalysts for selective hydrodeoxygenation of biomass-derived platform molecules. Green Chem 21(14):3744-3768

55. Li XL, Zhai ZJ, Tang CM et al (2016) Production of propionic acid via hydrodeoxygenation of lactic acid over $\mathrm{Fe}_{x} \mathrm{O}_{y}$ catalysts. RSC Adv 6(67):62252-62262

56. Li XL, Pang J, Zhang J et al (2019) Vapor-phase deoxygenation of lactic acid to biopropionic acid over dispersant-enhanced molybdenum oxide catalyst. Ind Eng Chem Res 58(1):101-109

57. Tanabe K (1987) Niobic acid as an unusual acidic solid material. Mater Chem Phys 17(1-2):217-225

58. Zhu R, Zhou GY, Gong BX et al (2020) Cascade conversion of furancarboxylic acid to butanediol diacetate over $\mathrm{Pd} / \mathrm{C}$ and $\mathrm{La}(\mathrm{OTf})_{3}$ catalytic system. Appl Catal A 608:117888

59. Gilkey MJ, Mironenko AV, Vlachos DG et al (2017) Adipic acid production via metal-free selective hydrogenolysis of biomass-derived tetrahydrofuran-2,5-dicarboxylic acid. ACS Catal 7(10):6619-6634

60. Gilkey MJ, Balakumar R, Vlachos DG et al (2018) Adipic acid production catalyzed by a combination of a solid acid and an iodide salt from biomass-derived tetrahydrofuran-2,5-dicarboxylic acid. Catal Sci Technol 8(10):2661-2671

61. Gilkey MJ, Cho HK, Murphy BM et al (2020) Catalytic adipic acid production on zeolites from biomass-derived tetrahydrofuran-2,5-dicarboxylic acid. ACS Appl Energy Mater 3(1):99-105

62. Nakagawa Y, Tomishige K (2011) Catalyst development for the hydrogenolysis of biomass-derived chemicals to value-added ones. Catal Surv Asia 15:111-116

63. Tomishige K, Nakagawa Y, Tamura M (2017) Selective hydrogenolysis and hydrogenation using metal catalysts directly modified with metal oxide species. Green Chem 19(13):2876-2924

64. Tomishige K, Nakagawa Y, Tamura M (2020) Taming heterogeneous rhenium catalysis for the production of biomassderived chemicals. Chin Chem Lett 31(5):1071-1077

65. Tomishige K, Nakagawa Y, Tamura M (2020) Design of supported metal catalysts modified with metal oxides for hydrodeoxygenation of biomass-related molecules. Curr Opin Green Sustain Chem 22:13-21

66. Liu LJ, Asano T, Nakagawa Y et al (2020) One-pot synthesis of 1,3-butanediol by 1,4-anhydroerythritol hydrogenolysis over a tungsten-modified platinum on silica catalyst. Green Chem 22(8):2375-2380

67. Aihara T, Miura H, Shishido T (2020) Investigation of the mechanism of the selective hydrogenolysis of $\mathrm{C}-\mathrm{O}$ bonds over a Pt/ $/ \mathrm{WO}_{3} / \mathrm{Al}_{2} \mathrm{O}_{3}$ catalyst. Catal Today 352:73-79

68. Wang J, Yang M, Wang AQ (2020) Selective hydrogenolysis of glycerol to 1,3-propanediol over Pt-W based catalysts. Chin J Catal 41(9):1311-1319

69. Asano T, Nakagawa Y, Tamura M et al (2020) Hydrogenolysis of tetrahydrofuran-2-carboxylic acid over tungsten-modified rhodium catalyst. Appl Catal A 602:117723

70. Tamura M, Tamura R, Takeda Y et al (2014) Catalytic hydrogenation of amino acids to amino alcohols with complete retention of configuration. Chem Commun 50(50):6656-6659 
71. Tamura M, Tamura R, Takeda $Y$ et al (2014) Insight into the mechanism of hydrogenation of amino acids to amino alcohols catalyzed by a heterogeneous $\mathrm{MoO}_{x}$-modified Rh catalyst. Chem Eur J 21(7):3097-3107

72. Li MX, Li GY, Li N et al (2014) Aqueous phase hydrogenation of levulinic acid to 1,4-pentanediol. Chem Commun 50(12):1414-1416

73. Nakagawa Y, Tamura R, Tamura M et al (2015) Combination of supported bimetallic rhodium-molybdenum catalyst and cerium oxide for hydrogenation of amide. Sci Technol Adv Mater 16:014901

74. Takeda Y, Nakagawa Y, Tomishige K (2012) Selective hydrogenation of higher saturated carboxylic acids to alcohols using a $\mathrm{ReO}_{x}-\mathrm{Pd} / \mathrm{SiO}_{2}$ catalyst. Catal Sci Technol 2(11):2221-2223

75. Tamura M, Nakagawa Y, Tomishige K (2020) Recent developments of heterogeneous catalysts for hydrogenation of carboxylic acids to their corresponding alcohols. Asian J Org Chem 9(2):126-143

76. Van de Vyver S, Román-Leshkov Y (2013) Emerging catalytic processes for the production of adipic acid. Catal Sci Technol 3(6): 1465-1479

77. Mahmoudi H, Mahmoudi M, Doustdar O et al (2017) A review of Fischer Tropsch synthesis process, mechanism, surface chemistry and catalyst formulation. Biofuel Eng 2(1):11-31

78. Wang HM, Male J, Wang Y (2013) Recent advances in hydrotreating of pyrolysis bio-oil and its oxygen-containing model compounds. ACS Catal 3(5):1047-1070

79. Han YL, Gholizadeh M, Tran CC et al (2019) Hydrotreatment of pyrolysis bio-oil: a review. Fuel Proc Technol 195:106140

80. Wang XC, Arai M, Wu QF (2020) Hydrodeoxygenation of ligninderived phenolics: a review on the active sites of supported metal catalysts. Green Chem 22(23):8140-8168

81. Nakagawa Y, Ishikawa M, Tamura M et al (2014) Selective production of cyclohexanol and methanol from guaiacol over $\mathrm{Ru}$ catalyst combined with $\mathrm{MgO}$. Green Chem 16(4):2197-2203

82. Ishikawa M, Tamura M, Nakagawa Y et al (2016) Demethoxylation of guaiacol and methoxybenzenes over carbon-supported Ru-Mn catalyst. Appl Catal B 182:193-203

83. Li CC, Nakagawa Y, Tamura M et al (2020) Hydrodeoxygenation of guaiacol to phenol over ceria-supported iron catalysts. ACS Catal 10(24):14624-14639

84. Skoog E, Shin JH, Saez-Jimenez V et al (2018) Biobased adipic acid - the challenge of developing the production host. Biotechnol Adv 36(8):2248-2263

85. Shiramizu M, Toste FD (2013) Expanding the scope of biomass-derived chemicals through tandem reactions based on oxorhenium-catalyzed deoxydehydration. Angew Chem Int Ed 52(49):12905-12909

86. Li XK, Wu D, Lu T et al (2014) Highly efficient chemical process to convert mucic acid into adipic acid and DFT studies of the mechanism of the rhenium-catalyzed deoxydehydration. Angew Chem Int Ed 53(16):4200-4204

87. Zhang HF, Li XK, Su XY et al (2016) Production of adipic acid from sugar beet residue by combined biological and chemical catalysis. ChemCatChem 8(8):1500-1506

88. Shin N, Kwon S, Moon S et al (2017) Ionic liquid-mediated deoxydehydration reactions: green synthetic process for biobased adipic acid. Tetrahedron 73(32):4758-4765

89. Larson RT, Samant A, Chen JB et al (2017) Hydrogen gasmediated deoxydehydration/hydrogenation of sugar acids: catalytic conversion of glucarates to adipates. J Am Chem Soc 139(40):14001-14004

90. Lin JC, Song HY, Shen XR et al (2019) Zirconia-supported rhenium oxide as an efficient catalyst for the synthesis of biomassbased adipic acid ester. Chem Commun 55(74):11017-11020
91. Shi HX, Zhang LF, Wu YD et al (2021) Production of adipic acid derivatives from D-glucaric acid by hydrodeoxygenation mediated with hydroiodic acid. Catal Lett 151(2):338-343

92. Wang Y, Deng WP, Yan LF et al (2021) Efficient catalysts for green synthesis of adipic acid from biomass. Angew Chem Int Ed 60(9):4712-4719

93. Meessen P, Vogt D, Keim W (1998) Highly regioselective hydroformylation of internal, functionalized olefins applying Pt/ Sn complexes with large bite angle diphosphines. J Organomet Chem 551(1-2):165-170

94. Wu DD, Chen Z, Jia ZB et al (2012) Synthesis of dimethyl adipate from cyclopentanone and dimethyl carbonate over solid base catalysts. Sci Chin Chem 55(3):380-385

95. Nobbs JD, Zainal NZB, Tan J et al (2016) Bio-based pentenoic acids as intermediates to higher value-added mono- and dicarboxylic acids. ChemistrySelect 1(3):539-544

96. Marckwordt A, El Ouahabi F, Amani H et al (2019) Nylon intermediates from bio-based levulinic acid. Angew Chem Int Ed 58(11):3486-3490

97. Obara N, Hirasawa S, Tamura M et al (2016) Oxidative cleavage of vicinal diols with the combination of platinum and vanadium catalysts and molecular oxygen. ChemCatChem 8(9):1732-1738

98. Nakagawa Y, Sekine D, Obara N et al (2017) Oxidative C-C cleavage of ketols over vanadium-carbon catalysts. ChemCatChem 9(17):3412-3419

99. Hatakeyama K, Nakagawa Y, Tamura M et al (2020) Efficient production of adipic acid from 2-methoxycyclohexanone by aerobic oxidation with a phosphotungstic acid catalyst. Green Chem 22(15):4962-4974

100. Rogers O, Pattisson S, Engel RV et al (2020) Adipic acid formation from cyclohexanediol using platinum and vanadium catalysts: elucidating the role of homogeneous vanadium species. Catal Sci Technol 10(13):4210-4218

101. Duale K, Zięba M, Chaber P et al (2018) Molecular level structure of biodegradable poly(delta-valerolactone) obtained in the presence of boric acid. Molecules 23(8):2034

102. Pinkos R, Bauduin C, Paul A et al (2011) Process for preparing delta-valerolactone in the gas phase. U.S. Patent 0237806

103. Adkins H, Billica HR (1948) The hydrogenation of esters to alcohols at 25-150 . J Am Chem Soc 70(9):3121-3125

104. Mock GH (1981) Process for preparing adipic acid with recovery of glutaric acid and succinic acids. U.S. Patent 4254283

105. ten Brink GJ, Arends IWCE, Sheldon RA (2004) The BaeyerVilliger reaction: new developments toward greener procedures. Chem Rev 104(9):4105-4124

106. Hara T, Hatakeyama M, Kim A et al (2012) Preparation of claysupported Sn catalysts and application to Baeyer-Villiger oxidation. Green Chem 14(3):771-777

107. Saikia PK, Sarmah PP, Borah BJ et al (2016) Stabilized $\mathrm{Fe}_{3} \mathrm{O}_{4}$ magnetic nanoparticles into nanopores of modified montmorillonite clay: a highly efficient catalyst for the BaeyerVilliger oxidation under solvent free conditions. Green Chem 18(9):2843-2850

108. Xing C, Tan R, Hao PB et al (2017) Graphene oxide supported chlorostannate (IV) ionic liquid: Brønsted-Lewis acidic combined catalyst for highly efficient Baeyer-Villiger oxidation in water. Mol Catal 433:37-47

109. Verrier C, Moebs-Sanchez S, Queneau Y et al (2018) The Piancatelli reaction and its variants: recent applications to high addedvalue chemicals and biomass valorization. Org Biomol Chem 16(5):676-687

110. Lange JP, Price R, Ayoub PM et al (2010) Valeric biofuels: a platform of cellulosic transportation fuels. Angew Chem Int Ed 49(26):4479-4483 
111. Yu ZH, Lu XB, Xiong J et al (2019) Transformation of levulinic acid to valeric biofuels: a review on heterogeneous bifunctional catalytic systems. Chemsuschem 12(17):3915-3930

112. Weng RG, Yu ZH, Xiong J et al (2020) Effects of water in the heterogeneous catalytic valorization of levulinic acid into $\gamma$-valerolactone and its derivative. Green Chem 22(10):3013-3027

113. Rackemann DW, Doherty WOS (2011) The conversion of lignocellulosics to levulinic acid. Biofuel Bioprod Biorefin 5(2):198-214

114. Pileidis FD, Titirici MM (2016) Levulinic acid biorefineries: new challenges for efficient utilization of biomass. Chemsuschem 9(6):562-582

115. Karanwal N, Verma D, Butolia P et al (2020) One-pot direct conversion of levulinic acid into high-yield valeric acid over a highly stable bimetallic $\mathrm{Nb}-\mathrm{Cu} / \mathrm{Zr}$-doped porous silica catalyst. Green Chem 22(3):766-787

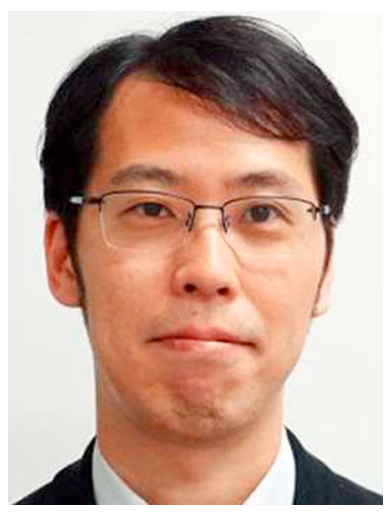

Yoshinao Nakagawa obtained his Ph.D. in 2005 from Graduate School of Engineering, the University of Tokyo, under the guidance of Prof. N. Mizuno. After four years of postdoctoral research at the University of Tokyo, he joined the research group of Keiichi Tomishige at University of Tsukuba. He moved to Tohoku University and became an assistant professor in 2010 . Since 2013, he has been an associate professor. His current research interests are catalytic oxidation and reduction of biomass-related compounds.

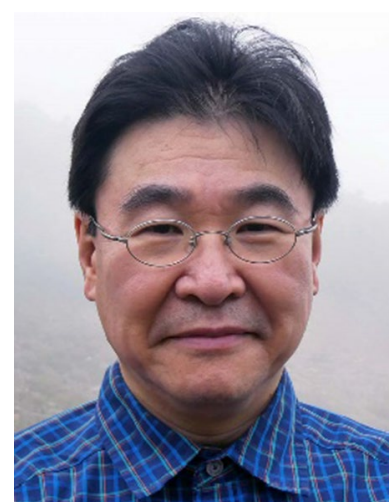

Keiichi Tomishige received his B.S., M.S. and Ph.D. from Graduate School of Science, Department of Chemistry, the University of Tokyo, with Prof. Y. Iwasawa. During his Ph.D. course in 1994, he moved to Graduate School of Engineering, the University of Tokyo, as a research associate and worked with Prof. K. Fujimoto. In 1998, he became a lecturer, and then he moved to Institute of Materials Science, University of Tsukuba, as a lecturer in 2001. Since 2004, he has been an associate professor,

Graduate School of Pure and Applied Sciences, University of Tsukuba. Since 2010, he is a professor, School of Engineering, Tohoku University. His research interests are the development of heterogeneous catalysts for 1) production of biomass-derived chemicals, 2) non-reductive $\mathrm{CO}_{2}$ conversion to value-added chemicals and 3) reforming for the production of renewable hydrogen from biomass. He is Associate Editor of Fuel Processing Technology (2014-), Editorial Board of Applied Catalysis A (2009-), International Advisory Board of ChemSusChem (2015-), Editorial Board of Green Chemistry (2017-), Editorial Advisory Board of ACS Omega (2018-), and International Advisory Board of ChemCatChem (2021-). 